\title{
Drug Promotion and Self-Medication Practices in Lagos, Nigeria
}

\author{
Johnson Oluwole Ayodele, Imodoye School of Criminology, Lagos, Nigeria
}

https://orcid.org/0000-0002-1297-4043

\begin{abstract}
The study examines the effects of drug promotional practices and self-medication behaviour on public health in Lagos. It used a multistage sampling method to select 315 respondents. The researcher selected 12 in-depth interviewees and six focus group discussants to provide qualitative data based on his knowledge of their relevance. The data were analyzed. The logistic regression analysis indicated that drug promotions were less than once more likely to trigger self-medication behaviour among residents relative to being a rule-breaking activity. The study concludes that self-medication endangers public health in Lagos. It suggests the partnership of the stakeholders to promote public drug education, provide free healthcare for all, and criminalize unethical drug promotion practices in Lagos.
\end{abstract}

\section{KEYWORDS}

Diseases, Lagos, Nigeria, Public Health, Rule Violation, Self-Medication, Unethical Drug Promotion

\section{INTRODUCTION}

The promotion of medicines in Africa is inherently tied to their user-driven effectiveness. This traditional practice validates the saying that the taste of the pudding lies in the eating. Before the advent of orthodox-medical practice, traditional medicines were the sole anchors of public-health insurance against diseases in Africa. Then, there were no structured drug-promotion media whose effects transcended the face-to-face transaction. Thus, verbal testimonies connected drug patronage to mainstream awareness, without a fee. Oblivious of individual differences in body chemistry, users of traditional drugs advertised the medical preparations that healed them to individuals whose ailments produced similar symptoms to theirs. This user-driven practice increased the network of prospective consumers of traditional medicines. Since traditional medicines were informally structured, its advertisement too was essentially informal. Therefore, in non-western settings, the contemporary use of the western drug is one of the vestiges of colonialism that boost the self-medication of western medicines in developing African countries such as Nigeria.

\section{Background}

Self-medication is the use of drugs to treat self-diagnosed disorders or symptoms, or the continued use of a prescribed drug for a lengthened or persistent disease or symptom (Afridi et al., 2015). Drug promotion practices are communication approaches by which an individual or organization transmits the perceived benefits that potential consumers could draw from the use of the advertised product and services (Ijoma et al., 2010). However, in the context of western drugs, promotion practices have become monetized economic occupations in contemporary Nigeria. Concerns that compel 
individuals to self-medicate recklessly include stress-freedom, cost-effectiveness, time economy, and the insignificance of the issue to warrant the attention of a doctor (Ayanwale, Okafor, \& Odukoya, 2017), the nauseating attitude of health workers... (Ocan et al., 2014).

Worldwide, the literature identifies Over-the-counter (OTC) and Prediction-Only-Medicines (POM) as the drug administration types open to consumers for self-medication trials. The global prevalence of self-medication is estimated between $10.3 \%$ and $87 \%$ subject to the population studied and method adopted (Bertoldi et al., 2014). Self-medication shows in the studies conducted in Europe to have 68\% prevalence (Jain et al., 2011), 84\% in Pakistan (Afridi et al., 2015), 78\% in Saudi Arabia (Al Rasheed et al.. 2016, in Kuwait, Nepal, and India 92\%, 59\% and 31\% (Jain et al., 2011) respectively, it is between 40.7-81.8\% in African countries (Ehigiator et al., 2010), specifically between 60\% and $90 \%$ in the southern Nigeria (Oyelola et al., 2010), where the present study site is situated. From the above, research evidence exists to show that self-medication is 'a common practice in developed and developing countries' (Helal \& Abou-ElWafa, 2017, p.1).

As a significant component of the everyday self-care of the contemporary individual (Almasdy $\&$ Sharrif, 2011), the documented cumulative flaws (Ruiz, 2010) of self-medication practices have been extensively studied (Afolabi et al., 2010). However, very little is known about how the drug promotion practices predispose residents to the self-medication practices that threaten public health in Lagos. Therefore, this study has four main objectives. First, examine the extent of drug promotion practices in the context of Lagos. Second, assess the self-medication practices of residents. Third, investigate the implications of drug promotion and self-medication practices of residents for public health in Lagos. Fourth, explore how the combined effects of drug promotion and self-medication practices of residents on public health can be reduced.

To realize these objectives, the study provides answers to the following questions. (i). To what extent do the residents of Lagos display the self-medication practices? (ii). What are the effects of drug promotion on the self-medication practices of residents? (iii). What are the effects of the selfmedication practices of the residents on urban health in Lagos? (iv). How can the effects of drug promotion and self-medication practices of residents on public health be reduced in Lagos? Could the drug promotion and self-medication practices of residents have worsened public health in Lagos? This is the gap that the present study hopes to fill in knowledge.

\section{Theoretical Framework}

The present study uses the health belief model and rational choice theory to explain the implications of drug promotion and self-medication practices for public health in Lagos.

\section{Health Belief Model}

Kasl and Cobb (1966, p. 246-266) hold that health behavior is "any activity undertaken by a person who believes himself to be healthy for preventing disease or detecting disease in an asymptomatic stage." This contrasts with illness behavior, "any activity is undertaken by a person who feels ill, to define the state of his health and of discovering a suitable remedy," and sick-role behavior, "the activity (that is) undertaken by those who consider themselves ill" to get "well." These three modes of behavior are not discrete because the edges between illness behavior and sick-role behavior are imprecise. The inability of the health belief model to simplify the justification for the choice which the respondent makes, the study uses the rational choice theory to complement it in this regard.

\section{The Rational Choice Theory}

The rational choice theory sees self-medication as a deliberate cost-driven action intended to ensure the recovery from illness with minimum stress in cases where this is viable. Therefore, the respondents rationally chose to listen to promotions of orthodox and unorthodox medicines based on which they displayed a self-medication disposition that favored the use of Paracetamol as the most common self- 
medicated drug as previously reported in studies conducted in Ondo and Plateau States of Nigeria (Omolase et al., 2007).

\section{Hypothesis}

There is a significant connection between the effects of the drug promotion practices and selfmedication practices among the residents that threaten public safety in Lagos.

\section{Method and Material}

The study was conducted in 2016 in Lagos State (Fig. 1). It derived its data from both primary and secondary sources. Respondents are all adults. The primary data were obtained through questionnaire administration and interviews to make qualitative data complement quantitative findings and produce a more robust research report. The study adopted a multistage sampling technique to select respondents who provided quantitative data as shown below: Stage 1: The study adopted the categorization of Lagos State into three Senatorial Districts (The NPC, 2006).

Figure 1 is the study site, in Nigeria. Note: the map of Nigeria shows the country as divided into 36 states and the capital Abuja. Lagos in the southwest was Nigeria's former federal capital.

\section{Figure 1. Map of Nigeria showing the location of Lagos}

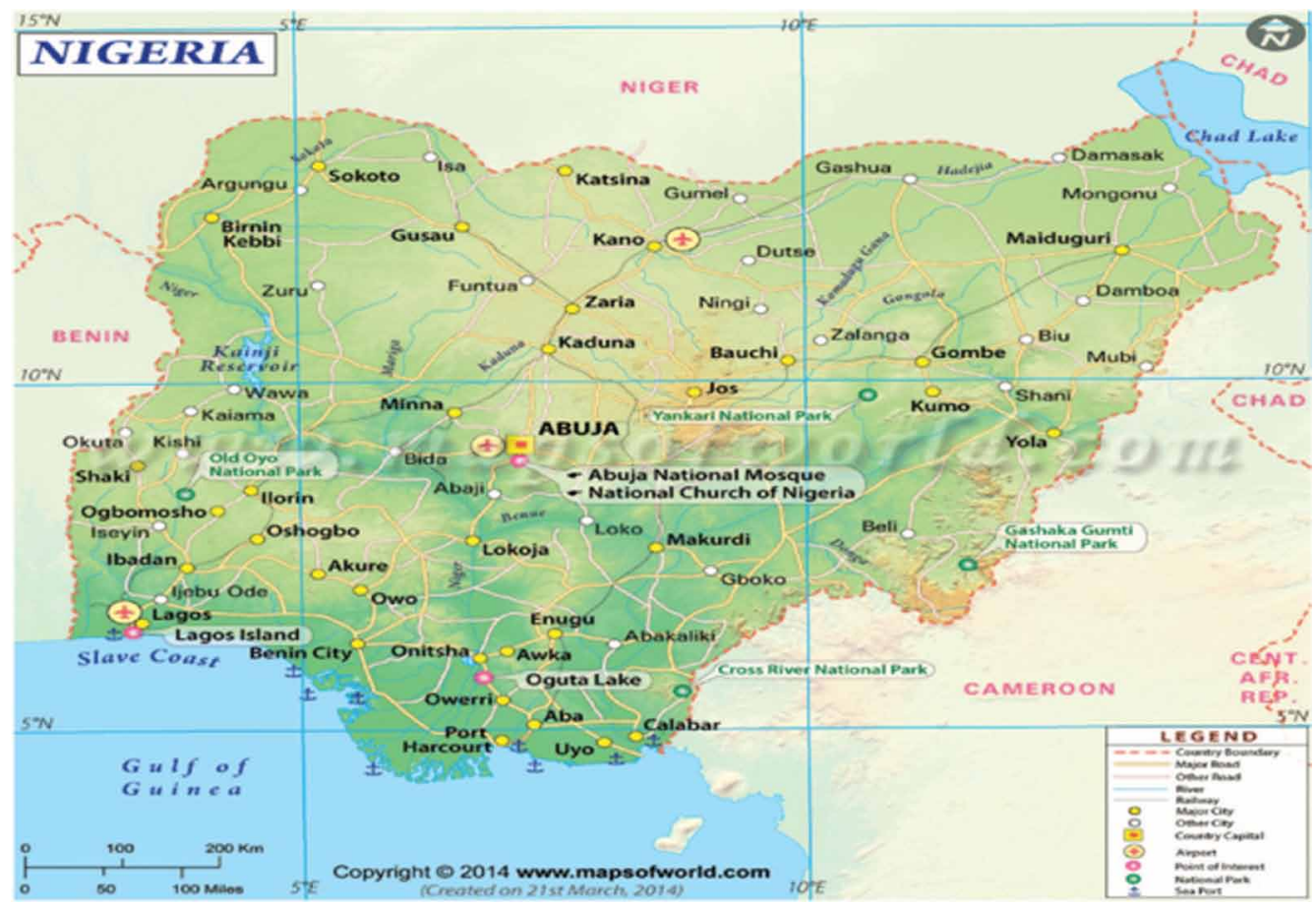

In stage 2, through a raffle draw, Ojo LGA was randomly selected from the Lagos West Senatorial District; Ibeju-Lekki LGA from the Lagos East Senatorial District and Lagos Island LGA from the Lagos Central Senatorial District. In stage 3, the study adopted the 245 wards created by the Federal Government as its sample frame. Therefore, informed by the differences in population sizes, 3 political wards were randomly selected from Ojo LGA, 2 from Lagos Island LGA and 1 from Ibeju Lekki LGA for inclusion in the study. Using random selection in stage 4, from each of the 3 political wards 
selected at Ojo LGA, 2 streets were selected; from each of the 2 political wards selected at Lagos Island LGA, 2 streets were selected; but from the 1 political ward selected from Ibeju Lekki LGA, 2 communities were selected because of the absence of clearly delineated streets. In the final stage, from each of the 3 selected streets from the political wards from the Ojo LGAs, 2 from Lagos Island LGA and 1 from Ibeju Lekki LGA, 25 houses were selected.

With an allowance of 5\% for attrition, 315 questionnaires were administered to each of the household representative people. In case more than a household occupied a house; the lottery method (yes or no) was used for the selection of household heads. A household representative person per house was interviewed. Overall, 300 questionnaires were found useful for the analysis. The study conducted twelve in-depth interviews (four from each of the selected LGA) with participants who are community people, drug promoters, and drug manufacturers selected based on the researcher's knowledge that they possessed the requisite understanding to provide qualitative data that will enable the study to achieve its stated objectives. Six focus group discussions were held with drug retailers, drug manufacturers, and drug-consuming residents (who were not part of the in-depth interview and questionnaire respondents) to provide complementary qualitative data.

\section{Ethical Considerations}

Core to credible scientific studies as the ethical considerations are worldwide, regrettably, in most developing countries of the world, most of the facilities required are individual-scholar provided, including funding. The absence of an IRB in my institutional affiliation may shock non-Africans. Nevertheless, it is the truth. Therefore, in most institutions where researchers could not avail themselves of an IRB approval because the structure is non-existent, the scholars develop reliable informedconsent forms which clearly explain the research and its rationale before the selected respondents voluntarily complete the questionnaire. When conducting the interviews, the researchers religiously complied with the guidelines in Nigeria's National Code of Health Research Ethics' Ethical Principles and Guidelines Section F (39).

\section{Results}

Below are the results in respect of the variables examined in respect of the four research questions which the present article addressed.

\section{Demographics}

The socio-demographic characteristics of the respondents reveal that $54.7 \%$ (see Table 1) of the respondents are males. The present study used a 5-year age grouping. A majority of the respondents (84.7\%) are married while slightly over $40 \%$ of the sampled population is less than 40 years of age. The pattern of education shows that $80.3 \%$ of the respondents had tertiary (Polytechnic and University) education leaving less than 3\% with no education. Among the ethnic groups in the study, Yoruba has the highest respondents $(66.7 \%)$. While a majority of the respondents $(61.7 \%)$ are Christians, a small majority (32.9\%) are traders. This was also reflected in the pattern of income of the respondents with only $29.3 \%$ earning between N24, 000-N28, 000 (\$67 and \$78) per month.

\section{The Extent of Self-Medication Practices of Residents in Lagos}

This section presents the extent of self-medication practices of the residents in urban Lagos. Data in Table 2 show that whereas $85 \%$ of the respondents acknowledged that urban residents ever used drugs not recommended by doctors, $91.6 \%$ admitted that they practiced self-medication. This summarizes the reality of the drug consumption practices of residents of urban Lagos because data also show that the prevalence of self-medication is as high as $97 \%$ of residents of Ojo LGA, Ibeju Lekki LGA (90\%) and Ikeja LGA (68\%). Effectively, analgesics are most commonly self-medicated in urban Lagos $(95 \%)$. That $88 \%$ of the respondents used tranquilizers suggests that their drug consumption pattern without prescription transcends the use of ordinary pain-relieving drugs. 
Table 1. Percentage distribution of selected variables

\begin{tabular}{|c|c|}
\hline Variable & $\begin{array}{c}\text { Frequency } \% \\
\quad \mathbf{N}=300\end{array}$ \\
\hline $\begin{array}{c}\text { Sex } \\
\text { Male } \\
\text { Female } \\
\text { Total }\end{array}$ & $\begin{array}{c}54.7 \\
45.3 \\
100.0\end{array}$ \\
\hline $\begin{array}{c}\text { Age } \\
26-30 \\
31-35 \\
36-40 \\
41-45 \\
46-50 \\
51 \text { and above } \\
\text { Total }\end{array}$ & $\begin{array}{c}8 \\
17.7 \\
15 \\
12.7 \\
15.3 \\
31.3 \\
100.0\end{array}$ \\
\hline $\begin{array}{c}\text { Marital Status } \\
\text { Single } \\
\text { Married } \\
\text { Widowed } \\
\text { Separated } \\
\text { Total }\end{array}$ & $\begin{array}{c}7.7 \\
84.7 \\
5.3 \\
2.3 \\
100.0\end{array}$ \\
\hline $\begin{array}{c}\text { Educational Qualification } \\
\text { No formal education } \\
\text { FSLC } \\
\text { WAEC } \\
\text { OND } \\
\text { HND/B.Sc. and above } \\
\text { Total }\end{array}$ & $\begin{array}{c}2.7 \\
2.7 \\
14.3 \\
20.6 \\
59.7 \\
100.0\end{array}$ \\
\hline $\begin{array}{c}\text { Religion } \\
\text { Christianity } \\
\text { Islam } \\
\text { Traditional } \\
\text { Total }\end{array}$ & $\begin{array}{c}61.7 \\
35.7 \\
2.66 \\
100.0\end{array}$ \\
\hline $\begin{array}{c}\text { Ethnicity } \\
\text { Igbo } \\
\text { Hausa } \\
\text { Yoruba } \\
\text { Total }\end{array}$ & $\begin{array}{c}30.7 \\
2.6 \\
66.7 \\
100.0\end{array}$ \\
\hline $\begin{array}{l}\text { Occupation } \\
\text { Trader } \\
\text { Civil servant } \\
\text { Retiree } \\
\text { Student } \\
\text { Total }\end{array}$ & $\begin{array}{c}51.3 \\
35.7 \\
9.7 \\
3.3 \\
100.0\end{array}$ \\
\hline $\begin{array}{c}\text { Income } \\
\text { N19,000- N23,000 } \\
\text { N24,000- N28,000 } \\
\text { N29,000- N33,000 } \\
\text { N34,000- N39,000 } \\
\text { N40,000 and above } \\
\text { Total }\end{array}$ & $\begin{array}{c}12 \\
29.3 \\
25.7 \\
15.3 \\
17.7 \\
100.0\end{array}$ \\
\hline
\end{tabular}

A female in-depth interviewee, who is a petty trader (a community person) at Ikeja, considered the extent to which she indulges in self-medication due to the ridiculous doctor/patient ratio and observed: 
Table 2. Extent of self medication in Lagos

\begin{tabular}{|c|c|c|c|}
\hline \multirow[b]{2}{*}{ Respondents } & \multicolumn{2}{|c|}{ Urban Residents Practise Self Medication } & \multirow[b]{2}{*}{ Total \% } \\
\hline & $\begin{array}{l}\text { Yes } \\
\% \mathbf{N}\end{array}$ & $\begin{array}{l}\text { No } \\
\% \mathbf{N}\end{array}$ & \\
\hline Ever Used Drugs not Doctor Prescribed & $85.0(255)$ & $15.0(45)$ & $100.0(300)$ \\
\hline Practise of Self Medication in Lagos & $91.6(271)$ & $8.3(25)$ & $100.0(300)$ \\
\hline \multicolumn{4}{|l|}{ Residence } \\
\hline Ikeja & $68.0(68)$ & $32.0(32)$ & $100.0(100)$ \\
\hline Ojo & $97.0(97)$ & $3.0(3)$ & $100.0(100)$ \\
\hline Ibeju Lekki & $90.0(90)$ & $10.0(10)$ & $100.0(100)$ \\
\hline Total & $85.0(255)$ & $45.0(15)$ & $100.0(274)$ \\
\hline \multicolumn{4}{|l|}{ Drugs Most Commonly Self-Medicated } \\
\hline Analgesics & $95.0(133)$ & $5.0(7)$ & $100.0(140)$ \\
\hline Blood tonic & $70.4(76)$ & $29.6(32)$ & $100.0(108)$ \\
\hline Intravenous Injection & $100.0(2)$ & $0.0(0)$ & $100.0(2)$ \\
\hline Sleeping drugs & $88.0(44)$ & $12.0(6)$ & $100.0(50)$ \\
\hline Total & $85.0(255)$ & $15.0(45)$ & $100.0(300)$ \\
\hline
\end{tabular}

If you visit any of the general hospitals in the neighborhood and see the experiences of sick-poor people, no one will blame low-income earners who opt for self-medication. When the absence of functional social welfare becomes a norm, a display of self-medication practices is a self-loving and patriotic duty.

Female IDI Respondent, Ikeja LGA. August 15, 2016

Another in-depth interview respondent, who is a chemist salesman at Ojo, expressed his anger at how some customers go behind to disparage their business and noted:

Human beings are complex. Most of the people who condemn chemist shops as abattoirs for sick Nigerians often patronize us at night. If self-medication is a crime, at that level, then almost all the residents of Lagos are criminals.

Male IDI Respondent, Ojo LGA. August 17, 2016

A male local government worker, who also is an in-depth respondent at Ibeju Lekki, observed:

Nothing can be more criminal about public governance than the citizens going to a public hospital to treat a headache only to go home with deadlier infectious diseases.

Male IDI Respondent, Ibeju Lekki LGA. August 19, 2016

The focus group discussion participants noted that the residents relied heavily on self-medication for their health-care needs for different reasons in Lagos. There is a consensus among the focus group discussants across the selected areas that there is a decay of public health institutions causing a loss of public faith in the health-delivery status of orthodox medicine. If indeed, the orthodox option is efficient, the elites will not always rush overseas for medical care. The discussants concluded that if anything was lawbreaking, it was not the people's use of self-medication but the neglect of public 
hospitals by the elites who allowed the decline of medical services to fertilize the culture of selfmedication.

\section{The Effects of Drug Promotion on Self-Medication Practices of Residents}

This section presents the effects of the drug promotion practices on the self-medication practices of the residents and public health in Lagos. For scientific investigations to show how lawbreaking practices motivate respondents to embrace self-medication so that policymakers could address the practice and its numerous effects, the present study probed into the effects of drug promotion on self-medication practices. Data in Table 3 indicate that radio advertising (92.3\%) and mobile advertising cabs (92. $2 \%$ ) were the most commonly used drug promotion media to drive self-medication practices among respondents in Lagos.

Making his contribution, a male in-depth respondent, who is also a civil servant at Ojo, noted:

The media of drug promotion are so diverse and penetrative that there are no nooks and crannies that their impacts are not felt in Lagos state. Assuming a resident is too preoccupied at his/her workplace that he/she misses radio and television drug promotions; it is unlikely that such a person will avoid them in the commuter buses or the mobile weekend-drug promotions especially in the streets.

Male IDI Respondent, Ojo LGA 2016.

Table 3. Extent of drug promotional media used in Lagos

\begin{tabular}{|c|c|c|c|}
\hline \multirow{2}{*}{$\frac{\text { Respondents }}{\text { Media of adverts }}$} & \multicolumn{2}{|c|}{ Extent of the Drug Promotion Media Used } & \multirow[t]{2}{*}{ Total \% } \\
\hline & Yes & No & \\
\hline Radio Adverts & $92.3(48)$ & $7.7(4)$ & $\begin{array}{c}100.0 \\
(52)\end{array}$ \\
\hline Tele Adverts & $69.7(53)$ & $30.3(23)$ & $\begin{array}{c}100.0 \\
(76)\end{array}$ \\
\hline Adverts in buses & $85.7(60)$ & $14.3(10)$ & $\begin{array}{c}100.0 \\
(70)\end{array}$ \\
\hline Mobile Advertising & $92.2(94)$ & $7.8(8)$ & $\begin{array}{l}100.0 \\
(102)\end{array}$ \\
\hline Total & $85.0(255)$ & $15.0(45)$ & $\begin{array}{l}100.0 \\
(300)\end{array}$ \\
\hline
\end{tabular}

A female biochemist, who is a technical staff of a drug manufacturing company at Ikeja and an in-depth respondent, observed that despite the restriction on open drug promotions because of the social sophistication of the environment, the impact of drug promotion is still everywhere felt. She added:

Drug promotion is a ubiquitous activity in Nigeria generally and Lagos in particular. Despite their restriction in Ikeja, drugs of different kinds and origins are still being promoted in ways that are inconsistent with the rules. I think it is a cultural thing. Among the Yoruba people, they call it 'ipolowo oja' (sales promotion or advertisement). Drug promoters drum up the efficacies of the promoted drugs, even when they sometimes do so in defiance of ethical limitations.

Female IDI Respondent, Ikeja LGA 2016. 
Moreover, the data in Table 4 show that respondents attributed a variety of effects which selfmedication practices of residents could have on public health. These effects ranged from persuasive drug promotion practices could enable residents to address their health issues through the self-help approach of self-medication (39\%), encourage them to abuse drugs $(31.7 \%)$, discourage going to hospitals to waste their time seeking consultation (19.5\%) and giving the impression that selfmedication is unsafe (self-destructive) $(9.8 \%)$.

Table 4. Drug promotional practices drive self medication behaviour in Lagos

\begin{tabular}{|c|c|c|c|c|c|}
\hline Effects of Promotion on Self Medication & $\begin{array}{c}\text { Encourage } \\
\text { residents } \\
\text { to abuse } \\
\text { drugs \% }\end{array}$ & $\begin{array}{c}\text { Enable } \\
\text { resident } \\
\text { to address } \\
\text { health } \\
\text { challenges } \\
\text { through } \\
\text { self-help } \\
\text { approach \% }\end{array}$ & $\begin{array}{c}\text { Discourage } \\
\text { going to } \\
\text { hospital to } \\
\text { waste time } \\
\text { seeking } \\
\text { consultation } \\
\%\end{array}$ & $\begin{array}{c}\text { Giving the } \\
\text { impression } \\
\text { that self- } \\
\text { medication } \\
\text { is unsafe\% }\end{array}$ & $\begin{array}{c}\text { Total } \\
\%\end{array}$ \\
\hline Yes & $31.7(78)$ & $39.0(96)$ & $19.5(48)$ & $9.8(24)$ & $\begin{array}{c}100.0 \\
(246)\end{array}$ \\
\hline No & $21.4(6)$ & $28.6(8)$ & $42.9(12)$ & $7.1(2)$ & $\begin{array}{c}100.0 \\
(28)\end{array}$ \\
\hline Total & $30.7(84)$ & $38.0(104)$ & $21.9(60)$ & $9.5(26)$ & $\begin{array}{c}100.0 \\
(274)\end{array}$ \\
\hline
\end{tabular}

Another in-depth respondent, a male mobile drug promoter who covers most developing areas of Ibeju Lekki, remarked jokingly:

Can fish triumph in the absence of water? At the present level of empowerment of the poor and virtually excluded Nigerians, the vulnerable citizens cannot ignore the services of roadside drug promoters. Male IDI Respondent, Ibeju Lekki LGA 2016.

The consensus of the focus group discussions is that the account of public health is incomplete without the activities of the drug promoters in Lagos state. They noted that though they are the conduit of rewarding drugs and accompanying information, they also, even if inadvertently, promote drugs that are sometimes withdrawn by public health monitoring agencies. The law enforcement agencies need to be awake, in this regard, to their civic duty of safeguarding public health in Lagos.

\section{The Effects of Self-Medication Practices of the Residents on Urban Health in Lagos}

This section presents the effects of the self-medication practices of the residents on urban health in Lagos. The data in Table 5 indicate that $73.3 \%$ of the respondents identified health complications such as incurable diseases (13.8\%), mental challenges (7.4\%) and death (5.5\%) as the major consequences of self-medication practices of the residents on urban health.

A male in-depth interview respondent, who is a fisherman at Ibeju Lekki LGA, examined the effects of self-medication practices of urban residents on public health and noted:

The well-dressed mentally-challenged youth you find everywhere on the streets of Lagos are not the victims of employment-induced depression. Most of them are products of long-term drug abuse resulting from self-medication. It is a critical issue deserving critical policy intervention. 
Table 5. The effects of self-medication practices of the residents on urban health in Lagos

\begin{tabular}{|c|c|c|c|c|c|}
\hline $\begin{array}{c}\text { Drug Promotions Drive Self } \\
\text { Medication }\end{array}$ & $\begin{array}{c}\text { Health } \\
\text { complications \% }\end{array}$ & $\begin{array}{c}\text { Death } \\
\%\end{array}$ & $\begin{array}{c}\text { Mental } \\
\text { Challenges \% }\end{array}$ & $\begin{array}{c}\text { Incurable } \\
\text { Diseases\% }\end{array}$ & Total \% \\
\hline Yes & $73.3(159)$ & $\begin{array}{c}5.5 \\
(12)\end{array}$ & $7.4(16)$ & $13.8(30)$ & $\begin{array}{c}100.0 \\
(217)\end{array}$ \\
\hline No & $76.5(39)$ & $0.0(0)$ & $11.8(6)$ & $11.8(6)$ & $\begin{array}{c}100.0 \\
(51)\end{array}$ \\
\hline Total & $73.9(198)$ & $\begin{array}{c}4.5 \\
(12)\end{array}$ & $8.2(22)$ & $13.4(36)$ & $\begin{array}{c}100.0 \\
(268)\end{array}$ \\
\hline
\end{tabular}

\section{Male IDI Respondent, Ibeju Lekki LGA 2016}

A female in-depth interview respondent, who also is a drug retailer at Ikeja LGA, considered the effects of self-medication practices of urban residents on public health and commented:

Although individuals in the drug-retail business are rendering legitimate services to their prospective customers, they contribute to the dangers which face public health in Lagos.

Female IDI Respondent, Ikeja LGA 2016

A male in-depth interview respondent at Ojo LGA, who is a traditional ruler, looked at the effects of self-medication from two different perspectives in his analysis and noted:

If self-medication is done within a moderate limit, it is functional for the system, the medical practitioners, and the stakeholders in general. Self-mediation becomes an inexcusable self-consuming act when it is used without supervision in situations requiring the expertise of appropriately trained medical personnel.

Male IDI Respondent, Ojo LGA 2016

Focus group discussants considered the widespread consequences of self-medication on urban health and agreed that the culture causes drug distribution control or retrieval of some drugs found harmful to human health by the research departments of health agencies very difficult. This failure may have terrible implications for public health in urban Lagos.

\section{Management of The Effects of Self Medication on Urban Health by The Stakeholders}

This section presents data on the management of the effects of self-medication on urban health by stakeholders. If the way blood capsules, sedatives, and antibiotics are being self-medicated is not reversed, it may make the management of drug consumption difficult for relevant agencies such as FMoH, NAFDAC, MRA, the Nigeria Medical Association (NMA) and the National Drug Law Enforcement Agency (NDLEA). This causes the present study to probe into what could be done to avert the health challenge which the failure to ensure control might engender. Therefore, data in Table 6 show that for the government to prevent the effects of self-medication on public health in urban Lagos, a small majority (30.5\%) suggested public drug education through enlightenment campaigns, criminalization of self-medication of POM medications and provide free health care for all $(24.8 \%)$ respectively and ban indiscriminate drug promotion (19.9\%).

Furthermore, the present study probed into what individuals could do to manage the selfmedication practices of urban residents, $41.8 \%$ of the residents said individuals should seek medical 
assistance from doctors, encourage neighbors to embrace responsible drug-use culture (22.7\%), and individuals to cultivate responsible drug-use culture (22\%). Respondents also considered the steps which drug manufacturers should take to manage the effects of self-medication in urban Lagos, $40.4 \%$ of the respondents suggested that drug manufacturers should embark on responsible drug promotion practices; control drug distribution networks to prevent drugs going into wrong hands $(32.6 \%)$, and subscribe to ethical best practices in product promotions (20.6\%).

Table 6. Steps stakeholders can take to manage self-medication behaviour

\begin{tabular}{|c|c|c|c|c|c|}
\hline \multirow{2}{*}{$\begin{array}{l}\text { The Effects of Self Medication On } \\
\text { Urban Health Manageable }\end{array}$} & \multicolumn{5}{|c|}{ What Government Can Do to Manage the Effects of Self Medication } \\
\hline & Mass education \% & $\begin{array}{l}\text { Criminalisation of self- } \\
\text { medication }\end{array}$ & $\begin{array}{c}\text { Ban reckless } \\
\text { drug } \\
\text { advertisement \% }\end{array}$ & $\begin{array}{l}\text { Provide Free Health } \\
\text { Care for all \% }\end{array}$ & $\begin{array}{c}\text { Total } \\
\%\end{array}$ \\
\hline Yes & $30.5(86)$ & $24.8(70)$ & $19.9(56)$ & $24.8(70)$ & $\begin{array}{l}100.0 \\
(282)\end{array}$ \\
\hline No & $0.0(0)$ & $33.3(2)$ & $33.3(2)$ & $33.3(2)$ & $\begin{array}{c}100.0 \\
(6)\end{array}$ \\
\hline Total & $29.9(86)$ & $25.0(72)$ & $20.1(58)$ & $25.0(72)$ & $\begin{array}{l}100.0 \\
(288)\end{array}$ \\
\hline \multirow{2}{*}{$\begin{array}{l}\text { The Effects of Self Medication On } \\
\text { Urban Health Can Be Managed }\end{array}$} & \multicolumn{5}{|c|}{ What Individuals Can Do to Manage the Effects of Self Medication } \\
\hline & $\begin{array}{l}\text { Seek medical } \\
\text { assistance of } \\
\text { doctors } \%\end{array}$ & $\begin{array}{l}\text { Cultivate responsible } \\
\text { drug use culture } \%\end{array}$ & $\begin{array}{c}\text { Encourage } \\
\text { neighbours to } \\
\text { embrace responsible } \\
\text { drug use culture \% }\end{array}$ & $\begin{array}{l}\text { Join a vanguard for the } \\
\text { campaign against self- } \\
\text { medication } \%\end{array}$ & $\begin{array}{c}\text { Total } \\
\%\end{array}$ \\
\hline Yes & $41.8(118)$ & $22.0(62)$ & $22.7(64)$ & $13.5(38)$ & $\begin{array}{l}100.0 \\
(282)\end{array}$ \\
\hline No & $22.2(4)$ & $11.1(2)$ & $55.6(10)$ & $11.1(2)$ & $\begin{array}{c}100.0 \\
(18)\end{array}$ \\
\hline Total & $40.7(122)$ & $21.3(64)$ & $24.7(74)$ & $13.3(40)$ & $\begin{array}{l}100.0 \\
(300)\end{array}$ \\
\hline \multirow{2}{*}{$\begin{array}{l}\text { The Effects of Self Medication On } \\
\text { Urban Health Can Be Managed }\end{array}$} & \multicolumn{5}{|c|}{ What Drug Manufacturers Can Do to Manage the Effects of Self Medication } \\
\hline & $\begin{array}{l}\text { Embark on } \\
\text { responsible drug } \\
\text { promotional } \\
\text { practices \% }\end{array}$ & $\begin{array}{l}\text { Control drug distribution } \\
\text { network to prevent } \\
\text { drugs going into wrong } \\
\text { hands } \%\end{array}$ & $\begin{array}{l}\text { Subscribe to } \\
\text { ethical best } \\
\text { practices } \\
\text { in product } \\
\text { promotions \% }\end{array}$ & $\begin{array}{l}\text { Meet their corporate } \\
\text { social responsibilities to } \\
\text { the community } \%\end{array}$ & $\begin{array}{c}\text { Total } \\
\%\end{array}$ \\
\hline Yes & $40.4(114)$ & $32.6(92)$ & $20.6(58)$ & $6.4(18)$ & $\begin{array}{l}100.0 \\
(282)\end{array}$ \\
\hline No & $11.1(2)$ & $66.7(12)$ & $22.2(4)$ & $0.0(0)$ & $\begin{array}{c}100.0 \\
(18)\end{array}$ \\
\hline Total & $38.7(116)$ & $34.7(104)$ & $20.7(62)$ & $6.0(18)$ & $\begin{array}{l}100.0 \\
(300)\end{array}$ \\
\hline
\end{tabular}

A male in-depth interviewee, who is a trader at the Alaba International Market, considered the risks to which drug consumers inadvertently expose themselves and suggested:

Medical doctors are the normative link between the sick and the use of western drugs. Therefore, when individuals consume drugs without doctors' advice, the risk they run is more than not taking drugs at all. Therefore, consuming western drugs without doctors' prescription is like committing graduated suicide. It is a crime in Nigeria.

Male IDI Respondent, Ojo LGA 2016 
A female in-depth interview respondent from Ikeja LGA, who is a public affairs analyst, looked at the role which the drug manufacturers could play to ensure that self-medication practices of drug consumers do not endanger public health. She noted:

Drug manufacturing is a critical component of Nigeria's health care delivery norm. All drug manufacturers should produce drugs for medical specifications in hygienically approved environments. Female IDI Respondent, Ikeja LGA 2016

A male in-depth interview respondent, who is a community leader at Ibeju Lekki LGA, examined the role which the government could play in the reduction of the effects of self-medication on the health of the residents of urban Lagos and suggested:

The government should monitor illegal domestic production and illicit importation of drugs to address the malaise from both ends. If the government disallows the illegal local manufacture and importation of drugs into Nigeria, the channels of distribution and use can be effectively monitored. Male IDI Respondent, Ibeju Lekki LGA 2016

A Focus group discussion at Ikeja became obsessed with the traditional drugs, its promotion and self-medication when a discussant painted a scenario of a possible diplomatic severance of relations with Nigeria in the event of an outbreak of international war and drugs are not allowed to come in, how would Nigeria manage her citizens' health? After a session of an all-inclusive brainstorming, the group agreed that Nigeria should go into an era of pharmaceutical decolonization by embarking on a medical revolution that will showcase their indigenous health services delivery system for domestic consumption and possible exportation. The discussants from Lagos Island suggested the inclusion of values of responsible self-medication as a subject in Nigerian schools to equip young learners with the understanding they require to function as rational adult users of self-medication. But the discussants at Ojo LGA insisted that for self-medication practices of the urban residents to respond favorably to control, the guidelines for drug promotion must be put under an observation that is loyal to the public good by a joint effort of all the stakeholders in public health.

Table 7 shows the logistic regression odds ratios on the association between drug promotional practices and self-medication practices of the residents of urban Lagos. That drug promotion practices drive the self-medication practices of the residents of urban Lagos were less than once less likely (>.01) to abuse drugs, address health challenges through self-help and discourage time-wasting hospital attendance to seek consultation relative to giving the impression that irresponsible selfmedication is self-destructive.

\section{Discussion}

This study was designed to examine respondents' perceptions of drug promotion and self-medication practices in Lagos, Nigeria. Based on the findings of the present study, respondents acknowledged a

Table 7. Distribution of Logistic Regression Odds Ratios on drug promotions and self-medication

\begin{tabular}{|l|l|l|}
\hline Variables & P values & Odds Ratios \\
\hline Giving the impression that self-medication is not criminal *(r) & & 1.000 \\
\hline Encourage residents to abuse drugs & .001 & 186 \\
\hline Enable resident to address health challenges through self-help approach & .000 & 071 \\
\hline Discourage going to hospital to waste time seeking consultation & .000 & 083 \\
\hline
\end{tabular}

*(r) reference category 
high prevalence of self-medication (91.6\%) of both (OTC) which can be harmlessly self-medicated and POM medicines which consumers self-medicated at their risks. The self-medication of both types of medicines constitutes a severe problem in Nigeria. The finding of the present study is consistent with that of Oyelola et al. (2010) which indicated that between 60-90\% of the population in some communities were involved in self-medication. However, it is at variance with the study of Bello et al. (2011) which found $19.2 \%$ in Nigeria.

A greater majority in the present study (91.9\%) used analgesics, through self-medication practices. This finding corroborates those of earlier studies of $92.3 \%$ of their respondents (Ayanwale et al., 2017) and $85 \%$ (Omolase et al., 2007), which admitted to self-medication respectively. The finding of the present study in respect of analgesics being the most self-medicated drugs is also consistent with the results of earlier studies conducted in Ondo, and Plateau States of Nigeria, as well as in many parts of India and the United Kingdom (Andualem \& Gebre-Mariam, 2004; Omolase et al., 2007; Afolabi et al., 2010). Considering this reality, the existence of different contexts for the rich and the poor, within the Lagos metropolis, does not allow for an extensive discussion in terms of access to health, its quality, and overall consumers' perceptions under patients' perception of health care service quality offered by COHSASA-Accredited hospitals in Nigeria. In contemporary Nigeria, the middle class has disappeared. The staffers of Chevron are not the typical Nigerians who will find self-medication attractive. They are elites who hardly patronize the general hospital, the specialized hospital for the average Nigerians whom most of the respondents in the present study represent. Except for habit formation, the rich have no business with the soaring self-medication incidence in Nigeria.

The finding of the present study that underscores the depth of radio and mobile advertising drove drug promotion disagrees with that of Ijoma et al. (2010) in south-eastern Nigeria which found that stickers, drug presentations/launches, and personal souvenirs were most commonly employed marketing strategies. Furthermore, the present study found that $73.3 \%$ of respondents identified health complications as the most striking effect of self-medication. On the safeguards for self-medication, the respondents suggested that drug manufacturers should engage in responsible drug promotional practices. In the event of war, one of the discussion groups imaginatively looked at the imposition of import restrictions on Nigeria. After brainstorming on the probability, the discussants called for the decolonization of medicines that will lead to the upgrade of Nigeria's traditional roots, herbs, and concoctions for internal use and possible exportation to earn foreign exchange. Granted that the idea of decolonization of medicine did not form part of the interest of the study instrument but came up from a single focus group discussion, it nevertheless seems justified when looked at in the larger context of its emergence as the serendipity of science.

\section{Limitations of The Study}

One important limitation of this study is that some respondents may have inadvertently provided incorrect information about their interactions with the two primary variables of the study, either by exaggerating or understating their experiences. This is one of the customary limitations of interview surveys in developing traditional communities. Nevertheless, as the demographics of the study show, the study gives considerable insights into the realities of the study interest in Lagos and Nigeria.

\section{CONCLUSION}

The study examined the implications of drug promotional practices and self-medication practices among the residents of Lagos for steady public health. It provided quantitative and qualitative data to show the extent and effects of the interactions between the two variables. The finding of the current study shows that the respondents practiced self-medication. However, a consensus exists among the focus group discussants across the selected areas that there is a decay of public health institutions that causes a loss of public faith in the health-delivery status of orthodox medicine. Fuelled by extensive and intensive radio and mobile advertising, aggressive drug promotion practices could persuade 
residents to adopt a self-help approach of self-medication. Moreover, the article identified incurable diseases, mental challenges, and death as the major consequences of self-medication practices of the residents on urban health.

For the government to prevent the recklessness arising from the effects of self-medication on public health in urban Lagos, the respondents wanted it to embark on public drug education through enlightenment campaigns. On the contributions of individuals, they suggested that they should seek medical assistance from doctors and drug manufacturers should embark on responsible drug promotion practices. Some discussants, however, suggested that Nigeria should go into an era of pharmaceutical decolonization through a medical revolution to showcase its indigenous health services delivery system for domestic consumption and possible exportation. Furthermore, the values of responsible self-medication should be included as a core subject in Nigerian schools to equip young learners with the understanding they require to function as rational adult users and not abusers of self-medication. 


\section{REFERENCES}

Afolabi, A. O., Akinmoladun, V. I., Adebose, I. J., \& Elekwachi, G. (2010). Self-medication profile of dental patients in Ondo State, Nigeria. Nigerian Journal of Medicine, 19(1), 96-103. doi:10.4314/njm.v19i1.52488 PMID:20232763

Afridi, M., Rasool, G., Tabassum, R., \& Shaheen, M. (2015). Prevalence and pattern of self-medication in Karachi: A community survey. Pakistan Journal of Medical Sciences, 31(5), 1241-1245. doi:10.12669/pjms.315.8216 PMID:26649022

Al Rasheed, A., Umar, Y. U., Alkhashan, H., Abdelhay, O., Alawwad, A., Al Aboud, A., \& Al Battal, S. (2016). Prevalence and predictors of Self-Medication with antibiotics in Al Wazarat Health Center, Riyadh City, KSA. BioMed Research International, 2016, 3916874. doi:10.1155/2016/3916874 PMID:26881218

Almasdy, D., \& Sharrif, A. (2011). Self-Medication Practice with Nonprescription Medication among University Students: A Review of the Literature. Archives of Pharmacy Practice (Mumbai), 2, 95-100.

Andualem, T., \& Gebre-Mariam, T. (2004). Self-medication practices in Addis Ababa: A prospective study. Ethiopian Journal of Health Sciences, 14, 1-11.

Ayanwale, M. B., Okafor, I. P., \& Odukoya, O. O. (2017). Self-medication among rural residents in Lagos, Nigeria. Journal of Medicine in the Tropics, 19(1), 65-71. doi:10.4103/jomt.jomt_51_16

Bello, F. A., Morhason-Bello, I. O., Olayemi, O., \& Adekunle, A. O. (2011). Patterns and predictors of self-medication amongst antenatal clients in Ibadan, Nigeria. Nigerian Medical Journal, 52(3), $153-157$. doi:10.4103/0300-1652.86124 PMID:22083501

Bertoldi, A. D., Camargo, A. L., Silveira, M. P. T., Menezes, A. M. B., Assuncao, M. C. F., Goncalves, H., \& Hallal, P. C. (2014). Self-medication among adolescents aged 18 years: The 1993 Pelotas (Brazil) birth cohort study. The Journal of Adolescent Health, 55(2), 175-181. doi:10.1016/j.jadohealth.2014.02.010 PMID:24713443

Ehigiator, O., Azodo, C. C., \& Ehikhamenor, E. E. (2010). Self-medication with antibiotics among Nigerian dental students. Tan dent j, 16(2), 48-53.

Helal, R. M., \& Abou-ElWafa, H. S. (2017). Self-Medication in University Students from the City of Mansoura, Egypt. Journal of Environmental and Public Health. doi:10.1155/2017/9145193 PMID:28479921

Ijoma, U., Onwuekwe, I., Onodugo, O., Aguwa, E., Ejim, E., Onyedum, C., \& Ugwuonah, G. et al. (2010). Effect of Promotional Strategies of Pharmaceutical Companies on Doctors' Prescription Pattern in South East Nigeria. Turk Silahli Kuvvetleri Koruyucu Hekimlik Bulteni, 9(1), 1-6.

Jain, S., Malvi, R., \& Purviya, J. K. (2011). Concept of Self-medication; a Review. International Journal of Pharmaceutical and Biological Archives, 2(3), 831-836.

Kasl, S. V. \& Cobb, S. (1966). Health behavior, illness behavior, and sick-role behavior. Arch Environ Health, 1(12), 246-266.

National Population Commission (NPC). (2006). NPC Releases 2006 Population Figures - Nigeria Village Square. Retrieved on Saturday, December 21, 2013, from www.thenewsng.com/modules/zmagazine/article. php?articleid $=12976$

Ocan, M., Bwanga, F., Bbosa, G. S., Bagenda, D., Waako, P., Ogwal-Okeng, J., \& Obua, C. (2014). Patterns and Predictors of Self-Medication in Northern Uganda. PLoS One, 9(3), e92323. doi:10.1371/journal.pone.0092323 PMID:24658124

Omolase, C. O., Adeleke, O. E., Afolabi, A. O., \& Afolabi, O. T. (2007). Self-medication amongst general outpatients in a Nigerian community hospital. Annals of Ibadan Postgraduate Medicine, 5, 64-67. PMID:25161435

Oyelola, F. T., Razaq, A., \& Eniola, O. (2010). Self-medication among hospitalized patients in selected secondary health facilities in South-Western Nigeria. Pharmacy Practice, 8, 233-237. PMID:25126146

Ruiz, M. E. (2010). Risks of self-medication practices. Current Drug Safety, 5(4), 315-323. doi:10.2174/157488610792245966 PMID:20615179 
Johnson Oluwole Ayodele was a lecturer and faculty member, Department of Sociology, Lagos State University .Ayodele is currently the Academic Director of Imodoye School of Criminology, Lagos, Nigeria. A specialist in Criminology, Victimology, Social Problems, Social Works, Sociology of Education and Sociology of Mass Communication, with a particular interest in victims' crime reporting to the police. He has done extensive work in Lagos, some in Ogun, Oyo and Osun states of Nigeria. His work has focused on social responses to victimization, police attitudes to victims, agba, ajobi, and ajogbe as structures of vigilantism among the egba people, women as victims of widowhood practices, subsidy withdrawal injustice, and marital rape. Ayodele has some of his works published in both local and reputable and scholarly international journals. Ayodele is the Editor of Global Perspectives on Victimisation Prevention and Analysis 